\title{
Intravenous progesterone elicits a more rapid induction of lordosis in rats than does SKF38393
}

\author{
CHERYL A. FRYE \\ Connecticut College, New London, Connecticut \\ and State University of New York, Albany, New York \\ and \\ LAURA E. BAYON and JILL VONGHER \\ Connecticut College, New London, Connecticut
}

\begin{abstract}
In ovariectomized (ovx), estradiol (E)-primed rats, progesterone (P) facilitates sexual receptivity within 2-30 min following intravenous (i.v.) administration. Intracerebroventricular infusion of $P$ or the dopamine receptor type 1-like (D1) agonist, SKF38393, increases lordosis in ovx, E-primed rats, and intracellular progestin receptor (PR) blockers attenuate P and SKF38393's facilitation of lordosis. The present experiments examined whether $P$ can have effects via $D 1$ receptors and compared the onset of P's and SKF38393's induction of lordosis following i.v. administration. Ovx rats $(N=20)$ with i.v. jugular catheters were primed daily with $2 \mu \mathrm{g} \mathrm{E}$ subcutaneously and were pretested for sexual receptivity. In Experiment 1, rats $(n=10)$ were repeatedly tested for receptivity 3-7, 15, 30, 60, and $120 \mathrm{~min}$ following i.v. infusion of $\mathrm{P}(2 \mu \mathrm{g})$, SKF38393 (100 ng), and propylene glycol vehicle $(0.2 \mathrm{cc})$. Progesterone increased postinfusion lordosis at all test times, whereas SKF38393's increases in lordosis were not statistically significant until $15 \mathrm{~min}$ following i.v. infusion, relative to lordosis following vehicle or pretest conditions in Experiment 1. In Experiment 2, rats ( $n=15 ; 5$ from Experiment 1, and 10 new subjects) received infusions of the antiprogestin, RU38486, the D1 antagonist, SCH23390, or vehicle followed by a second $\mathrm{P}$ or vehicle infusion. Although both RU38486 and SCH23390 blocked the facilitatory effects of $P$ on lordosis, their effects varied. RU38486 completely blocked P's effects, whereas SCH23390 did not. In Experiment 3, rats ( $n=15$, from Experiment 2) received infusions of RU38486, SCH23390, or vehicle followed by a second SKF38393 or vehicle infusion. RU38486 and SCH23390 both effectively blocked the facilitatory effects of SKF38393 on lordosis. In Experiment 4, rats ( $n=15$, from Experiment 3) received i.v. infusions of $P$, which rapidly and significantly increased the number of superthreshold spikes in the ventral tegmental area, but not in the ventral medial hypothalamus or in the parietal cortex. These data suggest that actions at intracellular progestin receptors do not account for all of P's effects to facilitate receptivity. Interestingly, although PRs may be involved in P and D1 ligand's activation of female sexual behavior, D1 receptors are not required for P's effects. However, i.v. $P$ rapidly and significantly alters neuronal activity in sites with the greatest concentration of dopamine neurons (ventral tegmental area $>$ ventral medial hypothalamus $\geq$ cortex).
\end{abstract}

The steroid hormone progesterone $(\mathrm{P})$ can have diverse effects. P's effects on female sexual behavior in rodents is well known, relative to P's mediation of nonreproductive behaviors (Beatty, 1992), despite the fact that P's induction of anesthesia within 1-2 min following intravenous (i.v.) administration was reported over 50 years

This research was supported by CAREER Grant IBN95-14463 from the National Science Foundation to C.A.F. The RU38486 was provided by a grant from Research Biochemicals International and the NIMH Chemical Synthesis Program. Special thanks to Bob LaFrance, Jim Lembo, and Rebecca Murphy, whose technical assistance contributed greatly to this research project. The critical comments of Cheryl McCormick and Sharon Ramos on this manuscript are also greatly appreciated. Correspondence should be addressed to C. A. Frye, The University at Albany-SUNY, Department of Psychology, Neuroendocrinology Laboratories-SS1 12, 1400 Washington Ave., Albany, NY 12084 (e-mail: cafrye@cnsunix.albany.edu). ago (Selye, 1941, 1942). $\mathrm{P}$ is localized diffusely in the rodent brain following tritiated $P$ administration, with areas of greatest concentration in the midbrain $>$ hippocampus $>$ hypothalamus $>$ cortex (Luttge \& Wallis, 1973; Luttge, Wallis, \& Hall, 1974; Whalen \& Luttge, 1971a, 1971b). These are areas that do not have the highest concentration of intracellular progestin receptors (PRs) (Sar \& Stumpf, 1973; Warembourg, Poulain, \& Jolivet, 1992). Effects of $P$ on appetitive, consummatory, cognitive, developmental, emotional, and reproductive behaviors (Majewska, 1987) may be due to ovarian, adrenal, or de novo synthesis of P within glial cells (Baulieu, Schumacher, Koenig, Jung-Testas, \& Akwa, 1996) and its subsequent regulation of neurotransmission (Agmo \& Soria, 1997; Biegon \& McEwen, 1982; Kow, Mobbs, \& Pfaff, 1994; Ward, Crowley, Zemlan, \& Margules, 1975), neurotrophic effects, autocrine/paracrine actions, actions at intracellular receptors, or a combination of the above. 
The complexity of P's functional effects, sites, and mechanisms of action has substantial implications but also represents a challenge in discerning the precise mechanism and site(s) of actions for specific behavioral effects of $P$. In rodents, the sequential action of estradiol (E) and $P$ on the hypothalamus and other sites, such as the preoptic area and the midbrain, coordinate sexual behavior and physiology so that mating occurs near the time of ovulation (Feder, 1984). The reliance of these sites on steroid hormones for sexual receptivity, which can be reliably and validly induced and quantified in terms of lordosis (a behavior with established neural circuitry), makes reproductive behavior a focused and, hence, ideal model system to examine mechanism(s) of P's action.

Sexual behavior has been successfully utilized as a behavioral assay to address P's mechanism of action. Using this approach, the conventional view of P's genomic actions via intracellular receptors has been broadened considerably to include modulation of intracellular PRs by ligands other than progestins and to substantiate the notion that there are other actions of $P$ that augment those at intracellular PRs. First, activation of intracellular PRs by $\mathrm{P}$ or the dopamine receptor subtype 1 (D1)-like agonist, SKF38393, facilitates female sexual behavior in rodents. This effect can be blocked by administration of PR or D1 antagonists (Mani, Allen, Clark, Blaustein, \& O'Malley, 1994; Mani, Blaustein, et al., 1994). Second, P facilitates receptivity when applied to the midbrain of ovariectomized (ovx), E-primed rodents that have had $P$ applied to the hypothalamus (Frye \& DeBold, 1992a; Frye \& Gardiner, 1996a, 1996b; Frye, Mermelstein, \& DeBold, 1992).

The rodent midbrain has few estrogen-induced intracellular PRs (Blaustein \& Turcotte, 1988; Frye \& Vongher, 1999a, 1999b; Munn, Sar, \& Stumpf, 1983). P rapidly facilitates sexual behavior (Frye \& DeBold, 1992a; Frye \& Gardiner, 1996a; Frye et al., 1992) and enhances neuronal firing (Rose, 1990) when applied to the midbrain, free or conjugated to a macromolecule. Midbrain infusion of PR antagonists (Frye \& Vongher, 1999a) and oligonucleotides (Frye \& Murphy, in press) do not influence P-induced receptivity; however, GABA agonists (Frye \& DeBold, 1992b; Frye \& Gardiner, 1996b) facilitate and GABA antagonists (Frye \& Gardiner, 1996b; Frye, Mermelstein, \& DeBold, 1993) inhibit P-induced receptivity. Findings of inhibition of receptivity following midbrain infusions of $P$ synthesis and metabolism blockers are also consistent with P's midbrain effects being secondary to metabolism (Frye \& Leadbetter, 1994) and/or increased synthesis of progestins (Vongher \& Frye, 1997) that can have subsequent actions at $\mathrm{GABA}_{\mathrm{A}}$ benzodiazepine receptor complexes (GBRs). Hence, $P$ may not be acting solely via PRs to influence lordosis. Other substrates, particularly within the midbrain, should be considered as loci for P's mechanism of action.

The mesocorticolimbic dopamine tract is a neural substrate for motivation, reward, and locomotion (Wise \& Rompre, 1989) and may modulate responsiveness to so- cial incentive cues. Not surprisingly, the dopamine system can mediate reproductive behaviors, and dopaminergic or adrenergic antagonists enhance the motivation of male rats to copulate (Hull, Bazzett, Warner, Eaton, \& Thompson, 1990; Kalra, Clark, \& Kalra, 1988). These antagonists also disturb maternal responsiveness in lactating rats (Giordano, Johnson, \& Rosenblatt, 1990). In female rodents, dopamine receptor agonists have been reported to facilitate (Everitt, Fuxe, \& Hokfelt, 1974; Foreman \& Moss, 1979; Meyerson, Carrer, \& Eliasson, 1974), to inhibit (Eliasson \& Meyerson, 1976; Foreman \& Moss, 1979; Meyerson, 1968), or to have biphasic effects on lordosis (Foreman \& Hall, 1987; Grierson, James, Pearson, \& Wilson, 1988; Sietnieks \& Meyerson, 1985). Although these findings are apparently contradictory, the disparities may be due to different hormonal milieu utilized that influence dopamine effects and due to the fact that some of the drugs used were not specific for dopamine receptor subtypes. Recent findings suggest that D2 receptors may mediate inhibitory effects on lordosis (Ahlenius, 1993; Grierson et al., 1988), whereas D1 and possibly D5 receptors may modulate lordosis facilitation (Apostolakis, Garai, Clark, \& O’Malley, 1996; Apostolakis, Garai, Fox, et al., 1996; Felicio \& Nasello, 1989; Mani, Allen, et al., 1994). Although is not clear which receptor subtypes mediate particular aspects of estrous behavior, it has been shown that PRs are important for dopamine ligands' facilitation of sexual behavior. For example, E-primed mice that are genetically bred to be lacking PRs (PRKOs) show reduced lordosis induction when P or dopamine ligands are administered, relative to lordosis seen in wild type control mice (Frye \& Vongher, 1999b; Mani et al., 1996). This suggests that unoccupied PRs are important for P's or SKF38393's facilitation of receptivity.

Because $P$ has been shown to have multiple mechanisms of action and diverse functional effects and because there is a behavioral link between $P$ and dopamine systems for facilitation of sexual behavior, we investigated (1) whether $\mathrm{P}$ has actions via $\mathrm{Dl}$ receptors, (2) the time course of $\mathrm{P}$ and SKF38393's effects to mediate lordosis, and (3) whether fast effects of i.v. P are associated with changes in neuronal activity in the midbrain.

\section{METHOD}

\section{Subjects}

Female rats $(N=20)$ were obtained from Charles River Laboratories (Kingston, NY) and were housed in the Laboratory Animal Care Facility at Connecticut College in polypropylene cages (45.7 $\times 30.5 \times 15.2 \mathrm{~cm})$ in a temperature-controlled room, with lights off between 0800 and 2000 . Food and water were continuously available in the rats' cages.

\section{Surgery}

The subjects' ovaries were removed via dorsal bilateral abdominal incisions using sodium pentobarbital $(40 \mathrm{mg} / \mathrm{kg}$ or to effect) as the anesthetic. A week later, ovx, nembutal-anesthetized rats were implanted with i.v., jugular catheters according to modified methods of McCormick, Smythe, Sharma, and Meaney (1995) and Gans and McClintock (1993). Briefly, the left jugular was exposed, and 
a silastic catheter was inserted toward the heart and secured in place by suturing it to the surrounding musculature. The distal end of the catheter was passed under the skin, exiting through a small incision at the base of the scalp. Once in place, the catheter was immediately flushed with heparinized saline. Similar daily flushing ensured subsequent patency. Following Experiment 3, the subjects were anesthetized for chronic electrode implantation with Rompun $(12 \mathrm{mg} / \mathrm{kg})$ and Ketamine $(70 \mathrm{mg} / \mathrm{kg})$ delivered in a single intraperitoneal injection. Stainless steel ( $\# 000)$ insect pins insulated with Epoxlite were implanted in the ventral medial hypothalamus (VMH; AP = $-2.0 ; \mathrm{DV}=-8.0$; Lat $= \pm 1.0$ ), the ventral tegmental area (VTA; $\mathrm{AP}=-5.3 ; \mathrm{DV}=-7.0 ;$ Lat $= \pm 0.4)$, and the parietal cortex $(\mathrm{AP}=$ $-3.8 ; \mathrm{DV}=-0.5 ; \mathrm{Lat}= \pm 2.2$ ). All coordinates were in millimeters, referenced from bregma, in the flat skull position (Paxinos \& Watson, 1986). Two stainless steel screws ( $\# 80 \times 1 / 8$ in.) fixed in the parietal cortex served as ground and indifferent electrodes. All leads were run to an Amphenol block assembly that was fixed to the skull with dental acrylate.

\section{Hormone, Drugs, and Infusion Conditions}

The ovx, catheterized rats $(N=20)$ were subcutaneously injected daily with $\mathrm{E}(2 \mu \mathrm{g})$ dissolved in sesame oil. Twenty-four hours following a second $E$ injection, females were pretested for sexual receptivity as described below. After the pretest, catheters were flushed with heparinized saline and one of the compounds noted below was administered over a $10-\mathrm{sec}$ period via the catheter in $0.2 \mathrm{ml}$ propylene glycol vehicle. This was followed by another infusion of $0.2 \mathrm{ml}$ heparinized saline. The i.v. dosages were modeled after those intracerebroventricular dosages that reliably produced changes in lordosis (Mani, Allen, et al., 1994). The i.v. infusion conditions were as follows: PR agonist progesterone, $2 \mu \mathrm{g}$; PR antagonist RU38486, $2 \mu \mathrm{g}$; D1 agonist $\mathrm{R}(+)$-SKF38393 hydrochloride, $100 \mathrm{ng}$; Dl antagonist $\mathrm{R}(+)-\mathrm{SCH} 23390$ hydrochloride, $100 \mathrm{ng}$; or propylene glycol vehicle, $0.2 \mathrm{cc}$. $\mathrm{E}$ and $\mathrm{P}$ were obtained from Sigma Chemical Co. (St. Louis); all other compounds were obtained from Research Biochemicals International (Natick, MA). The subjects were tested 7-10 times, with 1-3 days between each test, during which time no hormones were administered. Five animals were removed from Experiment $\mathbf{I}$ due to catheter failure. Five animals were tested in three conditions in Experiments $I$ and 4, and twice in Experiments 2 and 3. Ten subjects were tested twice in Experiments 2 and 3, and three times in Experiment 4.

\section{Behavioral Testing}

To test sexual receptivity, each experimental female was placed in a glass aquarium $(61 \times 32 \times 27 \mathrm{~cm})$ with a male until 10 mounts were received. The measure used to quantify sexual receptivity was the percentage of occurrences of the female displaying the stereotypical mating stance lordosis, after being contacted by the male (lordosis quotient; LQ). The intensity of each lordosis per contact was quantified according to the lordosis rating scale of Hardy and DeBold (1971). The number of aggressive responses following a mount or the number of proceptive actions preceding it was also recorded and quantified as per Frye, van Keuran, and Erskine (1996). The number of contacts that elicited a prolonged lordosis stance (greater than l sec) was also assessed. Following lordosis testing, the rats' sexual motivation was examined at each time point. The rats were put in a Y-maze, and the duration of time spent within one body length orienting to a male versus a female conspecific was recorded in a 120 -sec test (Frye, Bayon, Pursnani, \& Purdy, 1998). In Experiment $\mathrm{I}$, anxiolytic effects of i.v. infusions were examined by assessing open arm time (Dunn, Reed, Copeland, \& Frye, 1998) in a 5-min plus-maze task, which was conducted between the 5- and 15min test for sexual behavior and motivation.

\section{Electrophysiological Testing}

Twenty-four hours after surgery, the viability of electrical signals from each brain site was assessed for each subject. This recording consisted of placing the subject in a shielded aquarium for a period of $15 \mathrm{~min}$ prior to connecting the subject, via low-noise cabling, to a preamplifier (Harvard Apparatus 51531). Signals were bandpass-filtered $1 \mathrm{~Hz}$ to $40 \mathrm{kHz}$ and amplified 1,000 times. The amplified signal was passed to one channel of a storage oscilloscope (Tektronix 2201). The second channel of the oscilloscope was set to ground, and the trace position from this channel was adjusted to establish an amplitude threshold for electrical activity from each brain site. Electrical activity from the VMH, the VTA, and the parietal cortex was sampled individually against the indifferent electrode, and the amplitude threshold for each site was set at $>2$ times noise. Each session consisted of recordings from each of the three brain sites for a period of $5 \mathrm{~min}$, with the oscilloscope set on a 5-sec sweep time. The number of superthreshold spikes observed during each sweep was recorded.

In order to determine the latency of change in firing rates of the brain sites under investigation, each rat received $\mathrm{E}$ priming for 2 days. Twenty-four hours later, electrical activity was recorded from one of the three brain sites for a period of $5 \mathrm{~min}$ while the female was alone and another $5 \mathrm{~min}$ in the presence of a male. After completion of these recordings, each female received an i.v. infusion of $P$ $(2 \mu \mathrm{g}$ in $0.2 \mathrm{ml})$ through the catheter and was immediately placed back in the recording chamber with the male. Electrical activity was monitored from the same brain site for $5 \mathrm{~min}$. After a washout period of 1-3 days, this recording paradigm was repeated for each subject to provide recordings in the i.v. $P$ and vehicle conditions from each of the three brain sites with implanted electrodes. The initial recording site was randomized and subsequent recording sites were counterbalanced to prevent any possible order effects. Following each subjects's last recording session, an electrical current $(2 \mathrm{~mA}$ for $2-5 \mathrm{sec}$ ) was applied to the electrode. The subjects were then intracardially perfused with $0.9 \%$ saline, followed by $10.0 \%$ formalin. Fixed brains were later frozen, cut at $40 \mu \mathrm{M}$, and stained with cresyl violet to verify recording site.

\section{Procedure}

Experiment 1: Do $P R$ and D1 agonists influence lordosis responses? The rats $(n=10)$ were tested prior to and 3-7 (the " $5-\mathrm{min}$ test"), 15, 30, 60, and 120 min following i.v. infusion of P, SKF38393, or vehicle. After a washout period of 1-3 days, the subjects were retested in another condition until each subject received all three infusion conditions. Only 5 of 10 rats received all three tests, and, hence, only their data are included. The rats were randomly assigned to different infusion conditions initially, and their subsequent infusions were counterbalanced.

Experiment 2: Can RU38486 or SCH23390 attenuate P's increase in lordosis? Following a pretest, the rats $(n=15 ; 5$ from Experiment 1, and 10 additional ovx, catheterized rats) were randomly assigned to receive infusions of RU38486, SCH23390, or vehicle. This was followed $5,15,30$, and $60 \mathrm{~min}$ later with behavioral testing as described above. Then, a second infusion of $P$ or vehicle was administered, and the rats were tested 5, 15,30, and $60 \mathrm{~min}$ following the second infusion. After a washout period of 1-3 days, the subjects were tested after the same initial infusion followed by the alternate second infusion. Whether the rats received $P$ or vehicle first was randomly determined and counterbalanced, as was the distribution of experienced and novel subjects.

Experiment 3: Can RU38486 or SCH23390 block SKF38393's increase in lordosis? The rats ( $n=15$, those used in Experiment 2 ) were pretested and then infused i.v. with SCH23390, RU38486, or vehicle. They were tested 5, 15, 30, and 60 min later, as in Experiment 2 . The rats then received a second infusion of SKF38393 or vehicle and were retested for sexual receptivity $5,15,30$, and $60 \mathrm{~min}$ following the second i.v. infusion. After a washout period of $1-3$ days, the subjects were tested in the same condition, but the alternate secondary infusion was administered. Whether the rats received SKF38393 or vehicle at the initial test session was randomly assigned and counterbalanced. 
Experiment 4: Can IV $P$ rapidly alter electrical activity in the VMH, VTA, or parietal cortex? Following habituation to the recording chamber, electrode-implanted rats $(n=15$, those used in Experiment 3) were pretested for superthreshold spikes for $5 \mathrm{~min}$ with and without a male. The rats were similarly pretested following $E$ priming. The subjects were then i.v. infused with $P$ and retested for superthreshold spike frequency in a 5-min test. Whether the VMH, the VTA, or the cortex was initially recorded from was randomized and the subsequent recording site was counterbalanced to prevent any possible order effects. Additional conditions were not possible because of difficulty maintaining the patency of the catheters and the electrodes.

\section{Statistical Analyses}

For Experiment 1, a double repeated measures (condition $\times$ test time) two-way analysis of variance (ANOVA) was used to examine effects of infusion condition (vehicle, P, or SKF38393) and test time (pretest, $5,15,30,60$, or 120 min postinfusion) on $L Q$, lordosis rating (LR), aggression quotient, proceptivity quotient, and time spent with a male or time spent with a female. An ANOVA examined effects of infusion condition on open arm time in the plusmaze. For Experiment 2, a mixed-design three-way ANOVA with double repeated measures was utilized, with one between-subjects factor (initial infusion of vehicle, RU38486, or SCH23390) and two within-subjects factors (second infusion of vehicle vs. $P$ and test time pretest, 5, 15, 30, and $60 \mathrm{~min}$, pretest infusion $2,65,75,90$, and $120 \mathrm{~min}$ postinfusion 1). Experiment 3 was analyzed as was Experiment 2 except the within-subjects factor was second infusion of vehicle or SKF38393. Experiment 4 was analyzed with a two-way ANOVA, with two within-subjects factors, recording site (VMH, VTA, cortex) and test condition (with estrogen priming alone [alone], with estrogen priming with the male [with male], with estrogen priming, i.v. $\mathrm{P}$, and presence of male [post $\mathrm{P}$ with male]). Factors revealed as significant in the overall ANOVA were confirmed with ANOVAs at each time point so that Student Newman-Keuls post hoc tests could be used to ascertain differences among the conditions.

\section{RESULTS}

\section{Experiment 1: Intravenous Infusion of $P R$ and D1 Agonists Facilitate Lordosis Responses}

Infusion condition $[F(2,8)=20.62, p<.01]$ and test time $[F(5,20)=5.85, p<.05]$ affected LQs. Overall, irrespective of test time, i.v. infusion of $P$ was associated with a 76\% increase in LQs over vehicle infusion values. SKF38393 infusion increased LQs $28 \%$ above the levels seen following vehicle control infusion. Overall, irrespective of infusion condition (P or SKF38393), there were significant elevations above pretest LQ levels seen at every postinfusion time point. At the 5-, 15-, 30-, 60-, and 120 -min time points following i.v. infusions, LQs were increased $43 \%, 73 \%, 100 \%, 85 \%$, and $112 \%$, respectively, above pretest values. In addition to infusion condition and test time having salient individual influences on LQs, there was also an interaction between these variables $[F(10,40)=2.16, p<.10]$. This interaction may be attributed to i.v. $P$ producing the largest increases in postinfusion LQs, followed by SKF38393 and vehicle. As Figure 1 illustrates, the rise in LQ was most rapid and prominent following $P$ infusion and peaked at $30 \mathrm{~min}$. The maximum effect following SKF38383 did not quite achieve that seen following P: 120 min were required postinfusion to produce an effect of similar magnitude to the effect for $P$. The latency for SKF38393 to increase LQs was 15 min, compared with 3-7 min following $P$.

Effects of infusions on other parameters of sexual behaviors were congruous with those for LQs. Infusion condition $[F(2,8)=35.21, p<.01]$ and test time $[F(5,20)=$ $10.92, p<.01]$ had similar influence on the qualitative measure of lordosis, LRs (data not shown). There were no significant effects of infusion condition or test time on aggression quotients. However, there was a trend $[F(2,8)=$ $3.84, p<.10]$ for proceptivity quotients to be increased following $\mathrm{P}$ infusion $(M=5.9 \pm 3.4)$; but this may have been due to proceptivity quotients having a mean of 0 for SKF38393 and vehicle infusion conditions. Percentage of contacts $[F(2,8)=3.15, p<.10]$ that elicited a prolonged lordosis stance tended to increase following $P$ infusion $(M=8.1 \pm 3.7)$; however, this may have been due to negligible increases for SKF38393 and vehicle infusion conditions. There was an effect of time $[F(5,20)=$ $3.07, p<.05]$ and an interaction between time and infusion condition $[F(10,40)=3.07, p<.01]$, which was attributable to increases to $28 \%$ and $21 \%$ at the 5 - and 15 min post $P$ infusion tests.

Infusion condition $[F(2,8)=19.26, p<.01]$ and test time $[F(5,20)=2.770, p<.05]$ influenced choice of proximity to a male versus a female conspecific in the Y-maze. P infusion $(M=26.7 \pm 2.6)$ resulted in less time spent in proximity to the female than did SKF38393 $(M=47.2 \pm$ $4.8)$ or vehicle infusion $(M=34.8 \pm 4.9)$. However, the time spent in proximity to the male was inversely related to the duration of sexual contact. For example, on the pretest, 5-, 15-, 30-, 60-, and 120-min Y-maze choice tests, females spent an average of $61,58,47,44,45$, and $38 \mathrm{sec}$ with the male, respectively.

Plus-maze performance was influenced by i.v. infusion condition $[F(4,8)=6.26, p<.05]$. Open arm time was significantly increased following $\mathrm{P}(M=34.8 \pm 4.9)$, relative to SKF38393 $(M=17.0 \pm 4.0)$ or vehicle $(M=$ $15.0 \pm 1.8)$ infusions.

\section{Experiment 2: RU38486 or SCH 23390 \\ Attenuates P's Increase in Lordosis}

Over all time points, initial infusion condition $[F(2,12)$ $=7.650, p<.01]$ affected LQs and vehicle increased overall LQs, relative to infusion of RU38486 or SCH23390. The secondary infusion condition $[F(1,12)=6.91, p<$ $.05]$ also influenced LQs, and vehicle was associated with overall LQs that were lower, relative to $P$ infusion. Test time $[F(4,48)=3.19, p<.05]$ also significantly influenced LQs. Although there were no differences in LQs following the initial infusion, there were significant elevations in LQ above pretest levels at every time point following the second infusion. At the 65-, 75, 90-, and 120 -min time points following the first i.v. infusions, LQs were increased above pretest values $15 \%, 35 \%, 47 \%$, and $35 \%$, respectively. 


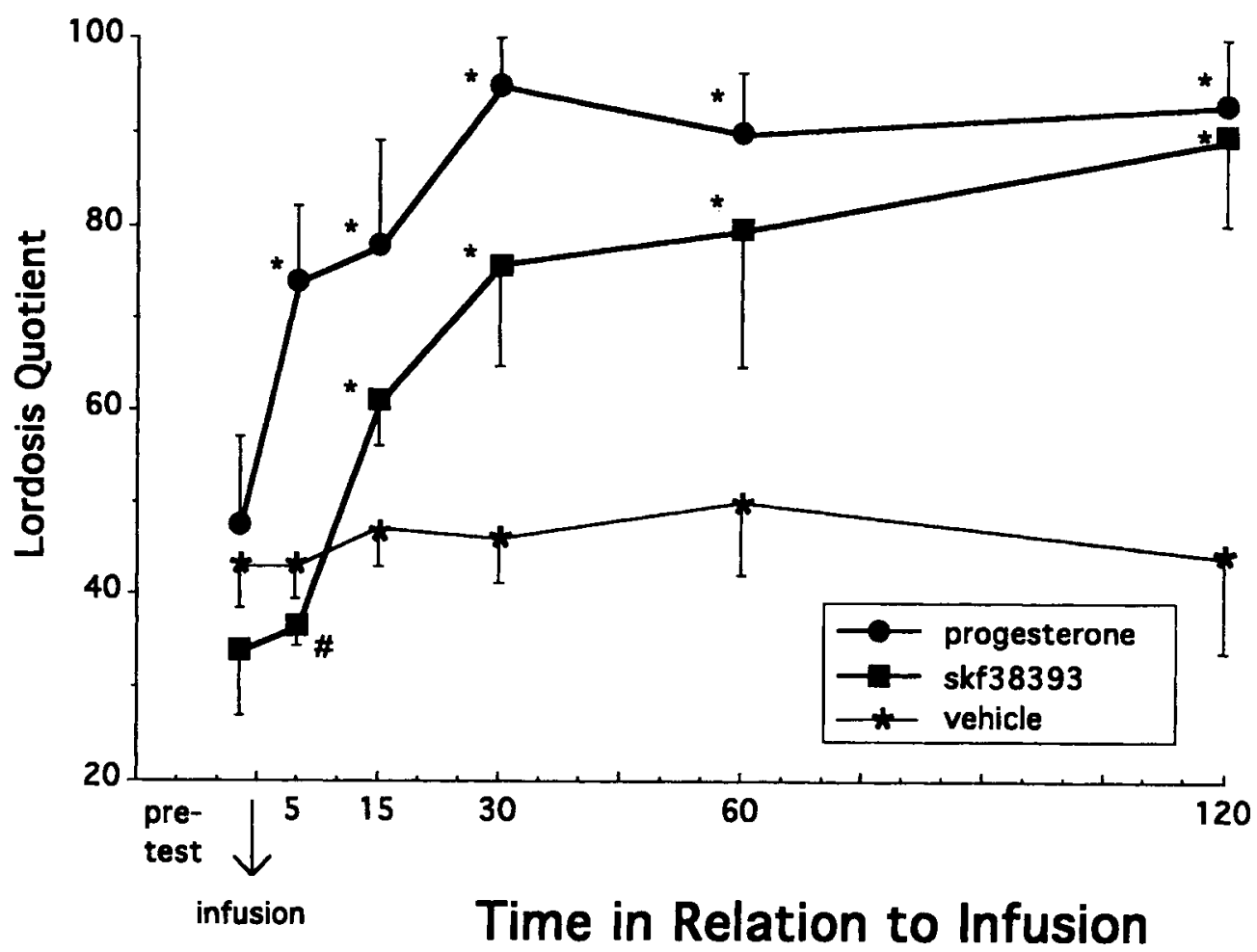

Figure 1. Mean lordosis quotients $\pm S E M$ are depicted for each time point, prior to having any infusion (pretest), immediately following infusion of $P$, SKF38393, or vehicle (5-min test), 15, 30, 60, and $120 \mathrm{~min}$ following infusion. Lordosis quotients were significantly increased at all post-P infusion time points when compared with the pretest value for $P$ and to vehicle control values at the same time point $\left({ }^{*} p<.01\right)$. Lordosis quotients were also significantly increased 15, 30, 60, and 120 min following SKF38393 infusion, relative to pretest values for SKF38393 or vehicle control values at the same time point $\left({ }^{\star} p<.01\right)$. Although $P$ produced greater increases in LQs than did SKF38393, there were no differences between 15, 30, 60, or 120 min following infusion. \# indicates that $P$ is significantly $(p<.05)$ different from SKF38393 at the indicated time point.

In addition to primary and secondary infusion conditions and test time having salient influences on LQs, there was a significant interaction between these variables $[F(8,48)=4.07, p<.01]$. This interaction was due to the significant increases in post-P infusion LQs (see Figure 2) following an initial vehicle or SCH23390 infusion.

Over all time points, lordosis ratings were also influenced by initial infusion condition $[F(2,12)=8.08, p<$ .01 ; data not shown]. There were no significant effects of infusion condition or test time on aggression quotients, proceptivity, or prolonged lordosis stance. However, there was an effect of secondary infusion condition $[F(1,12)=$ $16.74, p<.01]$ and test time $[F(4,48)=3.65, p<.01]$ on proximity to a male conspecific in the Y-maze. These effects may be summarized by the finding that duration of time spent with the male nearly doubled following the second infusion of $\mathrm{P}(M=62.6 \pm 2.9)$, relative to vehicle $(M=37.0 \pm 3.9)$. The duration of time spent in proximity to the female conspecific in the Y-maze was also influenced by the secondary infusion condition $[F(1,12)=$ $8.70, p<.05]$ and test time $[F(4,48)=7.28, p<.05]$. The duration of time spent with the female was reduced following a second infusion of $\mathrm{P}(M=23.5 \pm 1.8)$, relative to vehicle $(M=38.1 \pm 3.6)$.

\section{Experiment 3: RU38486 or SCH23390 \\ Attenuates SKF38393's Increase in Lordosis}

Test time $[F(4,48)=3.49, p<.05]$ significantly influenced LQs. Although there were no differences in LQs following the initial infusion, there were significant elevations in LQs above pretest levels at every time point following the second infusion. At the 65-, 75-, 90-, and 120 -min time points following the first i.v. infusions, LQs were increased above pretest values $5 \%$, $12 \%, 17 \%$, and $25 \%$, respectively. There was also a tendency for an interaction between secondary infusion conditions and test time to influence LQs $[F(4,48)=$ $2.23, p<.10]$. This interaction was attributable to the significant increases in post-SKF38393 infusion LQs (see Figure 3 ) following an initial vehicle infusion. Test time $[F(4,48)=6.42, p<.05]$ significantly influenced LRs (data not shown). 


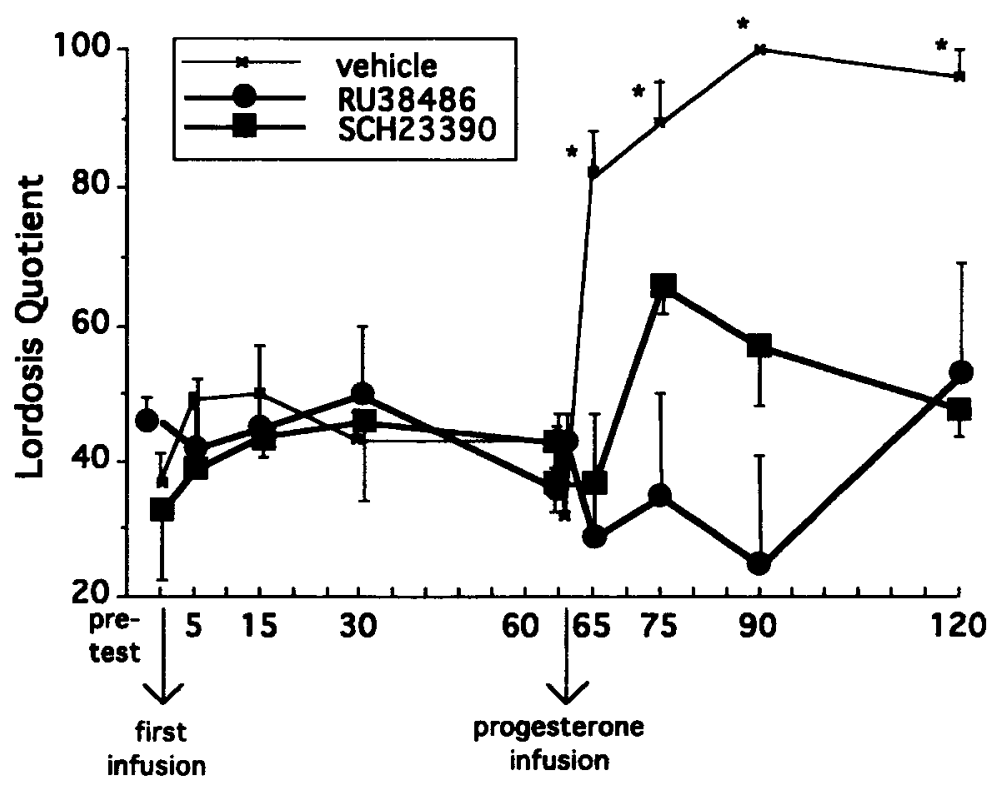

Time in Relation to First i.v. Infusion

Figure 2. Mean lordosis quotients $\pm S E M$ are shown following an initial infusion of RU38486, SCH23390, or vehicle and then following a second infusion of $P$ (data from second infusion of vehicle are not shown, since they were not different from lordosis in the first hour). Lordosis quotients were significantly increased, relative to pretest and all other values at the same time point, $5,15,30$, and $60 \mathrm{~min}$ post-P infusion, when the initial infusion was vehicle $\left({ }^{\star} p<.01\right)$. A similar effect was seen following $P$ infusion when the initial infusion was $S C H 23390$; however, increases in LQs were significant only 15 min following $P$ infusion.

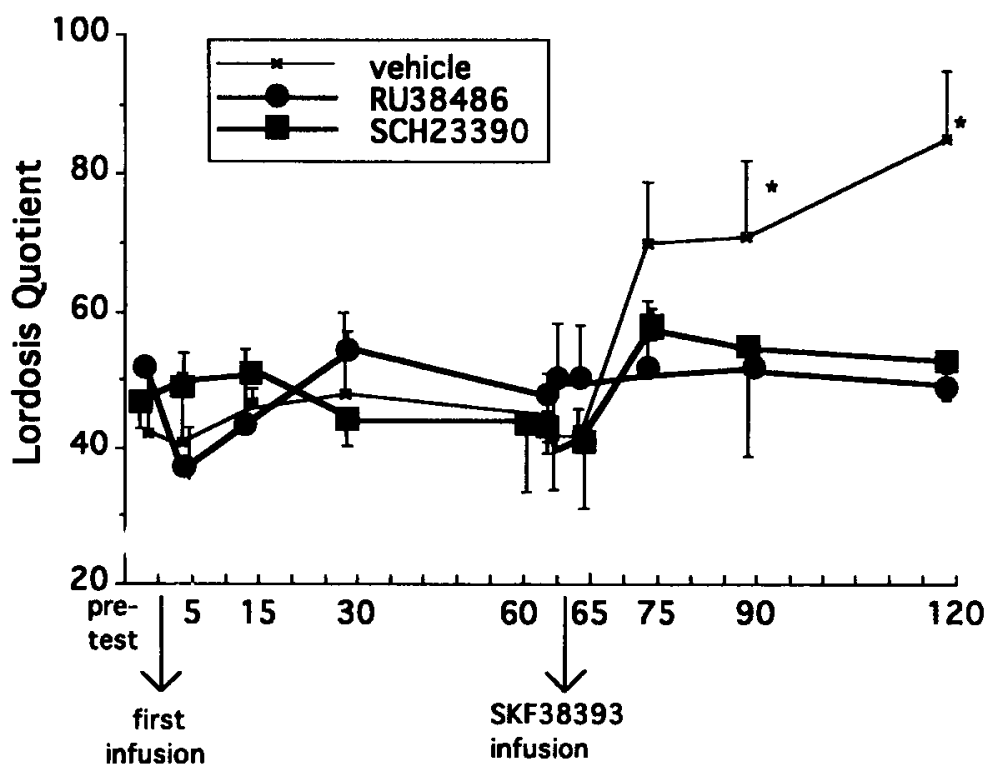

\section{Time in Relation to First i.v. Infusion}

Figure 3. Mean lordosis quotients $\pm S E M$ are illustrated following an initial infusion of RU38486, SCH23390, or vehicle and then following a second infusion of SKF38393 or vehicle. (Data from the second infusion of vehicle are not shown, since they were not different from lordosis in the first hour). Lordosis quotients were significantly increased, relative to pretest and all other infusions at the same time point, 15, 30, and $60 \mathrm{~min}$ post-SKF38393 infusion, when the initial infusion was vehicle $\left({ }^{*} p<.01\right)$. 
There was no significant effect of infusion condition or test time on aggression quotients, proceptivity, or prolonged lordosis stance. However, there was an interaction between primary and secondary infusion condition and test time $[F(8,48)=3.33, p<.01]$ on proximity to a male conspecific in the Y-maze. These effects may be attributed to the duration of time spent with a male being greatest following primary and secondary infusions of vehicle $(M=48.6 \pm 5.5)$. The duration of time spent in proximity to the female conspecific in the Y-maze also tended to be influenced by an interaction between secondary infusion condition and test time $[F(4,48)=2.27, p<.10]$. The duration of time spent with the female was increased following a second infusion of SKF38393 $(M=52.9 \pm 1.1)$, relative to vehicle $(M=39.7 \pm 2.3)$.

\section{Experiment 4: IV P Rapidly Alters Electrical Activity in the VTA > Parietal Cortex > VMH}

All recording sites were histologically verified as centrally located in the intended sites. The recording site $[F(2,12)=26.72, p<.01]$ significantly influenced, and the recording time $[F(2,24)=2.42, p<.10]$ tended to affect, the superthreshold spike frequency. Spike frequency was lowest in the $\operatorname{VMH}(M=197.5 \pm 30.0)$, greater in the cortex $(M=285.5 \pm 27.6)$, even greater in the VTA $(M=$ $465.5 \pm 36.1)$, and greatest following $\mathrm{P}$ infusion $(M=$ $360.7 \pm 58.6)$, and less when rats were alone $(M=294.4 \pm$
9.2) or with a male $(M=293.8 \pm 43.6)$. The interaction between recording site and condition $[F(4,24)=6.85$, $p<.01]$ was accounted for by the significant increase in VTA superthreshold spikes following $P$ infusion (see Figure 4).

\section{DISCUSSION}

These data include and suggest the following: (1) Intravenous administration of P or SKF38393, but not vehicle, significantly increases rats' LQs and LRs; however, the magnitude of the sexual enhancing effect of SKF38393 is less than that of $P$. This suggests that SKF38393 cannot mimic all of P's actions but may share a common mechanism with P. (2) Increased LQs and LRs occurred immediately following i.v. infusion of $P$ but did not occur until 15 min following administration of SKF38393. This rapid time course for $P$ is inconsistent with $\mathrm{P}$ having a solely genomic action but is sufficiently fast for a membrane-mediated action. (3) Pretreatment with RU38486 or SCH23390 attenuated P's and SKF38393's facilitative effects, but SCH23390 did not completely block P's facilitation of lordosis. This suggests that some actions associated with activation of PRs can mediate P's and SKF38393's effects and that stimulation of D1-like receptors contributes to P's effects but is not required for all of P's actions. (4) Infusion of i.v. P rapidly

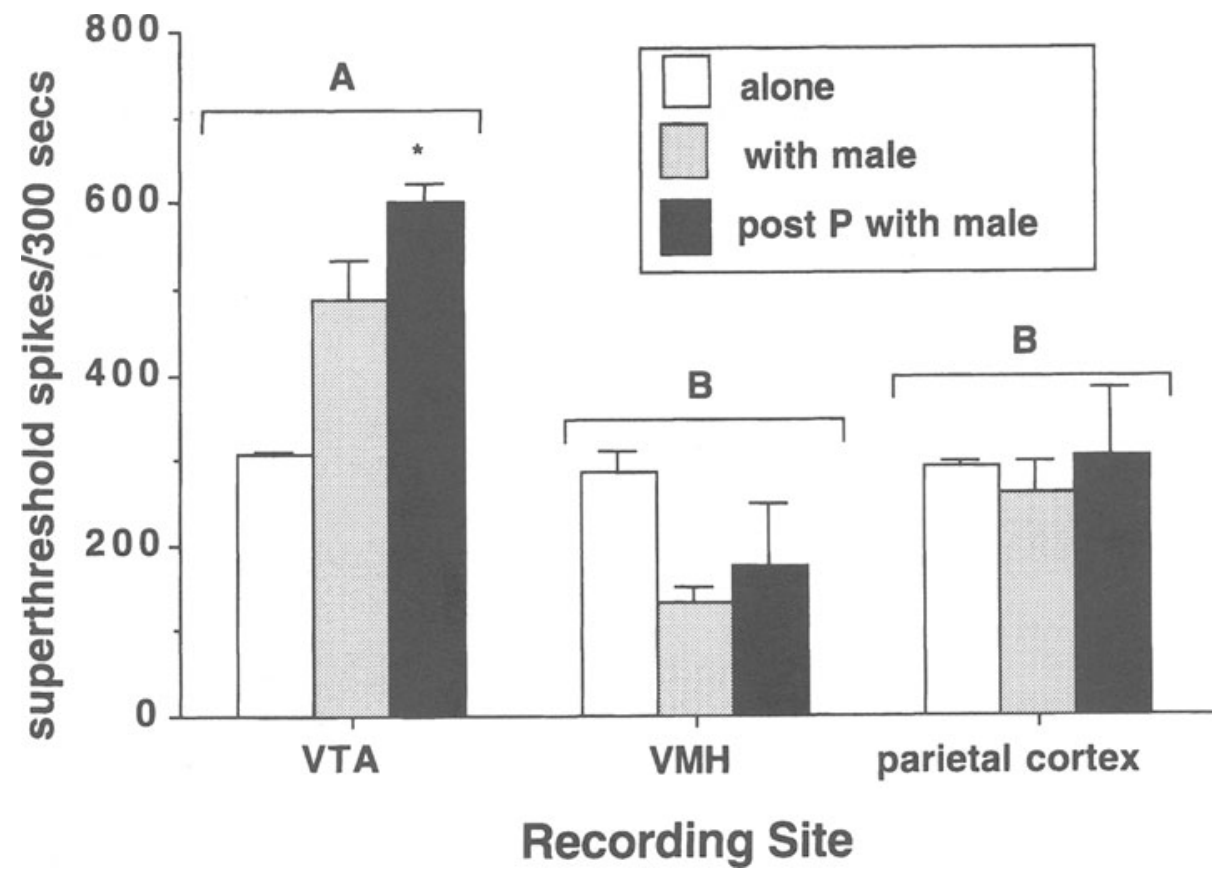

Figure 4. The average number of superthreshold spikes recorded from the VTA, the VMH, and the parietal cortex in a 300-sec test when the females were estradiol primed and alone (open bars), estradiol primed and with a male (striped bars), or estradiol primed, progesterone infused, and in the presence of a male (black bars). Firing rates were significantly $(p<.05)$ greater in the VTA than in the VMH or the cortex. Overall, sites with dissimilar letters are different from one another. VTA firing rates were also significantly increased following $P$ infusion, relative to other sites or infusion conditions $\left({ }^{*} p<.05\right)$. 
increased the frequency of superthreshold spikes in the VTA over those in the VMH or cortex. This suggests that the VTA may be involved in mediating the fast effects of i.v. P. Together, these data confirm that $P$ can exert fast actions to facilitate receptivity and suggest that the rapid actions of $P$ to facilitate receptivity may be augmented by mechanism(s) common to P and SKF38393.

These data are consistent with previous findings that indicate $P$ can produce rapid behavioral effects on nonreproductive and reproductive behavior. Anesthetic effects of $P$ occur within 30-180 sec following i.v. administration (Meyerson, 1967; Selye, 1941, 1942). The latency for induction of estrous behavior is more variable. For example, Lisk (1960) has reported that $95 \%$ of rats showed lordosis within 2-10 min of i.v. P $(25-400 \mu \mathrm{g})$ and that LQs were significantly increased $25 \%$ over vehicle values within 5 min of $200 \mu \mathrm{g}$ i.v. P infusion (Kubli-Garfias \& Whalen, 1977), whereas others have reported more modest $(10 \%)$ increases in LQs 15 min following $200 \mu \mathrm{g}$ $\mathrm{P}$ infusion (Glaser, Rubin, \& Barfield, 1983). In a direct comparison of P's anesthetic and lordosis-enhancing effects, Meyerson $(1967,1972)$ reported that P's anesthetic effects $(2.5-10 \mathrm{mg} / \mathrm{rat})$ occurred within $2-3 \mathrm{~min}$ of i.v. administration and generally dissipated within $10 \mathrm{~min}$, with the maximum duration of the anesthetic effect lasting $30 \mathrm{~min}$. The estrous-enhancing effects of i.v. $P(2.5-10 \mathrm{mg} /$ rat) were masked by P's anesthetic effects, because latencies for lordosis increased as higher dosages of $\mathrm{P}$ were administered. In general, lordosis onset was within 10-30 min following $0.5-5 \mathrm{mg}$ i.v. administration of $\mathrm{P}$, and the duration of this effect was $6-8 \mathrm{~h}$ (Meyerson, 1967, 1972).

In the present study, the latencies for P's estrousenhancing effects were among the shortest that have been reported. This was possibly due to the low dosage of P utilized ( $2 \mu \mathrm{g})$, which produced only slight anxiolysis. Our monitoring revealed that the i.v. P infusion condition produced a maximal $50 \%$ increase in open-arm activity in the elevated plus-maze 3-15 min following i.v. infusion but did not result in ataxic or anesthetic effects, as judged by no increase in righting latency. However, it should be noted that the facilitation of mating immediately following $P$ infusion was specific to lordosis induction, as evidenced by no alteration in proceptivity. A pilot study was performed in an attempt to examine the immediate effects of $P$ infusion in an ethological model of female sexual behavior in which the females initiated male-female interactions. After an initial contact with the male, females that were administered P or SKF38393 did not initiate further contact with the male. Although females did not initiate mating and, hence, their mating was not akin to that seen following $\mathrm{E}$ and systemic $\mathrm{P}$, the time course for $2 \mu \mathrm{g}$ i.v. $\mathrm{P}$ to induce lordosis and increase firing in the VTA was reminiscent of the latency for progestins to increase lordosis behavior when applied to the midbrain of E-primed rodents that have had P previously applied to the hypothalamus (Frye \& DeBold, 1992a, 1992b, 1993; Frye \& Gardiner, 1996a; Frye et al., 1992). The rapid latency for these effects is generally used to infer an ex- tragenomic mechanism, and, indeed, the associated literature suggests that the rapid midbrain (DeBold \& Frye, 1994a, 1994b) and anesthetic effects of P (Bitran, Purdy, \& Kellogg, 1993; Frye \& Duncan, 1994, 1995) may involve actions at GBRs.

The present data are consistent with this notion; however, limitations of the data should be considered. For example, it is possible that differences in P's or SKF38393's ability to initiate lordosis may be due to P's lipophilicity enhancing bioavailability of $P$ to the brain. Second, when administered systemically, SKF38393 may cause release of adrenal hormones, which might then indirectly induce changes in sexual behavior. Third, it is unclear how, but not surprising that, RU38486 could block rapid effects of $P$ even if its effects are membrane mediated, considering that blocking P's VMH genomic actions can attenuate the rapid membrane-mediated actions of $P$ in the VTA (Frye et al., 1992). Although the $E$ regimen utilized in the present study most likely activated PRs in the hypothalamus, PR induction in the VMH is less critical for manifestation of sexual receptivity in rats than in hamsters. Hamsters require genomic actions of $\mathrm{P}$ in the $\mathrm{VMH}$ prior to nongenomic effects being seen in the midbrain (Frye et al., 1992), whereas rats do not (Frye \& Gardiner, 1996a, 1996b). Fourth, the rats were repeatedly tested across experiments. Although controls for repeated testing were utilized within experiments, there were none across experiments. Hence, the increase in electrophysiological activity within the VTA in Experiment 4 may not have been due simply to the presence of $P$ and a stimulus male. One cannot rule out the possibility that this effect was due to sensitization of neurons within the VTA to previous exposures to $\mathrm{P}$ and to dopamine agonists and antagonists. This is particularly a concern since there is ample evidence for plasticity (sensitization) of the mesoaccumbal dopamine system. Further examination of these effects and their dose-response relationships, combined with site analysis, may clarify some of the above limitations.

Although these limitations must be taken into account, the findings of this study are important and reinforced by the literature. For example, it has been repeatedly shown that D1-like antagonists can block P or dopamine ligand's facilitation of lordosis (Apostolakis, Garai, Clark, \& O'Malley, 1996; Apostolakis, Garai, Fox, et al., 1996; Mani, Allen, et al., 1994). It has also been shown that dopamine can substitute for $P$ in the induction of lordosis (Whalen \& Lauber, 1986), while manipulation of dopamine and its receptors alters E- and P-induced lordosis (Ahlenius, 1993; Eliasson \& Meyerson, 1976; Everitt et al., 1974; Foreman \& Hall, 1987; Foreman \& Moss, 1979; Grierson et al., 1988; Meyerson, 1968; Meyerson et al., 1974; Sietnieks \& Meyerson, 1985). E and P have been shown to increase dopamine transmission (Dluzen \& Ramirez, 1989), and catecholamines increase PR expression (Blaustein, Brown, \& McElroy, 1986). Additionally, release of norepinephrine in the hypothalamus (Etgen, Ungar, \& Petitti, 1992) and dopamine in the striatum (Mermelstein \& Becker, 1995) is reported to accompany in- 
creases in female sexual behavior, and P and DI agonists are both capable of activating intracellular PRs (Apostolakis, Garai, Clark, \& O'Malley, 1996; Apostolakis, Garai, Fox, et al., 1996; Mani, Allen, et al., 1994; Mani, Blaustein, et al., 1994). This suggests that $P$ and dopamine interactions may represent cross talk between neurotransmitters, their receptors, and intracellular PRs in the integration of neural information in neuroendocrine systems.

Early research established that $P$ could have effects on nonreproductive (Meyerson, 1967; Selye, 1942) and reproductive (Lisk, 1960; Meyerson, 1967, 1972) behaviors within 2 min of i.v. injection. In order to address whether $\mathrm{P} /$ dopamine interactions mediate some of the more rapid effects of $P$ that have been reported, the time course of $P$ and SKF38393 to induce lordosis following i.v. administration was examined in the present study. The present data also indicate that the longer latency for SKF38393's facilitation of lordosis coincides with the maximal effect of $\mathrm{P}$, occurring between 15 and $\mathbf{3 0} \mathrm{min}$ following i.v. administration. It is possible that this long latency reflects sufficient time for actions at PRs. In short, $P$ may be capable of a fast but incomplete effect via actions at GBRs and D1 receptors, and these effects may be enhanced by further actions at PRs. This notion is congruent with data from rodents that show that rapid enhancements in lordosis are most readily elicited when progestins are applied to the midbrain, following genomic actions of $P$ in the hypothalamus (Frye \& DeBold, 1992a, 1993; Frye \& Gardiner, 1996a, 1996b). Whether P or dopamine may have some ability to mediate sexual receptivity via the few intracellular progestin receptors in the midbrain has not been thoroughly investigated.

It is also possible that the present facilitation of lordosis by SKF38393 was due to actions at PRs in the VMH. Cocaine applied to the $\mathrm{VMH}$, but not the arcuate or the preoptic area, facilitates sexual behavior in rats (Apostolakis, Garai, Clark, \& O'Malley, 1996; Apostolakis, Garai, Fox, et al., 1996). This effect is blocked by antisense oligonucleotide infusion specific for dopamine receptor mRNA or for PRs. Future work in our lab will investigate the role of the $\mathrm{P} /$ dopamine interaction involved in hypothalamic and midbrain mediation of lordosis.

In summary, the present findings reveal that P's effects may be mediated by D1 receptors; they also confirm that PRs are a likely substrate for some of P's and SKF38393's facilitation of lordosis. These findings are exciting because they may represent a behavioral example of an initial membrane-mediated action of $P$, followed by effects of $P$ and dopamine ligands at PRs and the dopamine system. Despite the many putative mechanisms by which $P$ may exert membrane and intracellular effects on lordosis in the rodent midbrain, the present data provide support for further investigation of $\mathrm{P} /$ dopamine interactions specifically directed at the midbrain, which is thought to be an important site for connection from the hypothalamus and integration of sensory and motivation inputs. The addition of these findings to the system through which $P$ enhances lordosis in the rodent midbrain may produce an effective model to examine cross talk between membrane and in- tracellular receptors necessary for the integration of neural information relevant for sexual receptivity.

\section{REFERENCES}

AGmo, A., \& SorIA, P. (1997). GABAergic drugs and sexual motivation, receptivity, and exploratory behaviors in the female rat. Psychopharmacology, 129, 372-381.

AHLENIUS, S. (1993). Brain monoaminergic neurotransmission in the mediation of lordosis behavior in the female rat. Neuroscience \& Biobehavioral Reviews, 17, 43-49.

apostolakis, E. M., Garai, J., Clark, J. H., \& O'Malley, B. W. (1996). In vivo regulation of central nervous system progesterone receptors: Cocaine induces steroid-dependent behavior through dopamine transporter modulation of D5 receptors in rats. Molecular Endocrinology, 12, 1595-1604.

apostolakis, E. M., Garai, J., Fox, C., Smith, C. L., Watson, S. J., Clark, J. H., \& O'Malley, B. W. (1996). Dopaminergic regulation of progesterone receptors: Brain D5 dopamine receptors mediate induction of lordosis by DI-like agonists in rats. Journal of Neuroscience, 16, 4823-4834.

Baulieu, E. E., Schumacher, M., Koenig, H., Jung-Testas, I., \& AKWA, Y. (1996). Progesterone as a neurosteroid: Actions within the nervous system. Cellular \& Molecular Neurobiology, 16, 143-154.

BEATTY, W. W. (1992). Gonadal hormones and sex differences in nonreproductive behaviors. In A. A. Gerall, H. Moltz, \& I. L. Ward (Eds.), Handbook of behavioral neurobiology: Vol. 11. Sexual differentiation (pp. 85-128). New York: Plenum.

Biegon, A., \& McEwEN, B. S. (1982). Modulation by estradiol of serotonin receptors in brain. Journal of Neuroscience, 2, 199-205.

Bitran, D., Purdy, R. H., \& KellogG, C. K. (1993). Anxiolytic effect of progesterone is associated with increases in cortical allopregnanolone and $\mathrm{GABA}_{\mathrm{A}}$ receptor function. Pharmacology, Biochemistry \& Behavior, 45, 423-428.

Blaustein, J. D., Brown, T. J., \& McElroy, J. F. (1986). Some catecholamine inhibitors do not cause accumulation of nuclear estrogen receptors in rat hypothalamus and anterior pituitary gland. Neuroendocrinology, 43, 143-149.

Blaustein, J. D., \& Turcotte, J. (1988). Estrogen receptorimmunostaining of neuronal cytoplasmic processes as well as cell nuclei in guinea pig brain. Brain Research, 495, 75-82.

DeBold, J. F., \& FrYe, C. A. (1994a). Genomic and non-genomic actions of progesterone in the control of female hamster sexual behavior. Hormones \& Behavior, 24, 445-453.

DeBold, J. F., \& FrYE, C. A. (1994b). Progesterone and the neural mechanisms of hamster sexual behavior. Psychoneuroendocrinology, 19, 563-579.

Dluzen, D. E., \& Ramirez, V. D. (1989). Progesterone effects upon dopamine release from the striatum of female rats: II. Evidence for a membrane site of action and the role of albumin. Brain Research, 476, 338-344.

Dunn, R. W., Reed, T. A. W., Copeland, P. D., \& Frye, C. A. (1998). The nitric oxide synthase inhibitor, 7-nitroindazole displays enhanced anxiolytic efficacy without tolerance in rats following subchronic administration. Neuropharmacology, 37, 899-904.

Eliasson, M., \& Meyerson, B. J. (1976). Comparison of the action of lysergic acid diethyamide and apomorphine on the copulatory response of the female rat. Psychopharmacology, 49, 301-306.

Etgen, A. M., Ungar, S., \& Petitti, N. (1992). Estradiol and progesterone modulation of norepinephrine neurotransmission-Implications for the regulation of female reproductive behavior. Journal of Neuroendocrinology, 4, 255-271.

EverITt, B. J., FuXE, K. J., \& HoKFELT, T. (1974). Inhibitory role of dopamine and 5-hydroxytryptamine in the sexual behavior of female rats. European Journal of Pharmacology, 29, 187-191.

FEDER, H. H. (1984). Hormone and sexual behavior. Annual Review of Psychology, 35, 165-200.

Felicio, L. F., \& NASEllo, A. G. (1989). Effect of acute bromopride treatment on rat prolactin levels and sexual behavior. British Journal of Medical \& Biological Research, 22, 1011-1014

Foreman, M. M., \& HaLL, J. L. (1987). Effects of D2-dopaminergic 
receptor stimulation on the lordotic response of female rats. Psychopharmacology, 91, 96-100.

Foreman, M. M., \& Moss, R. L. (1979). Role of hypothalamic dopaminergic receptors in the control of lordosis behavior in the female rat. Physiology Behavior, 22, 283-289.

Frye, C. A., Bayon, L. E., Pursnani, N. K., \& Purdy, R. H. (1998). Neurosteroids, $\mathrm{P}$ and $3 \alpha, 5 \alpha$-THP, enhance proceptivity, receptivity, and sexual motivation in female rats. Brain Research, 808, 72-83.

Frye, C. A., \& DeBold, J. F. (1992a). Muscimol facilitates sexual receptivity in hamsters when infused into the ventral tegmentum. Pharmacology, Biochemistry \& Behavior, 42, 879-887.

Frye, C. A., \& DeBold, J. F. (1992b). P-3-BSA, but not P-11-BSA, implants in the VTA rapidly facilitate receptivity in hamsters after progesterone priming to the VMH. Behavioural Brain Research, 53, $167-175$.

Frye, C. A., \& DeBold, J. F. (1993). $3 \alpha$-OH-DHP and $5 \alpha$-THDOC implants to the VTA facilitate sexual receptivity in hamsters after progesterone priming to the the VMH. Brain Research, 612, 130-137.

Frye, C. A., \& Duncan, J. E. (1994). Progesterone metabolites, effective at the $\mathrm{GABA}_{\mathrm{A}}$ receptor complex, attenuate pain sensitivity in rats. Brain Research, 643, 194-203.

Frye, C. A., \& Duncan, J. E. (1995). Estradiol benzoate potentiates neuroactive steroids' effects on pain sensitivity. Pharmacology, Biochemistry \& Behavior, 53, 27-32.

FrYe, C. A., \& GARDiner, S. G. (1996a). Progestins can have a membranemediated action in rat midbrain for facilitation of sexual receptivity Hormones \& Behavior, 30, 682-691.

Frye, C. A.. \& Gardiner, S. G. (1996b). Progestins can have a membranemediated action in rat midbrain for facilitation of sexual receptivity that is likely GABA mediated. Italian Journal of Anatomy \& Embryology, 101, 162-163.

Frye, C. A., \& Leadbetter, E. M. (1994). $5 \alpha$-reduced progesterone metabolites are essential in hamster VTA for sexual receptivity. Life Sciences, 54, 653-659.

Frye, C. A., Mermelstein, P. G., \& DeBold, J. F. (1992). Evidence for a non-genomic action of progestins on sexual receptivity in hamster VTA but not hypothalamus. Brain Research, 578, 87-93.

Frye, C. A., Mermelstein, P. G., \& DeBold, J. F. (1993). Bicuculline infused in the hamster ventral tegmentum inhibits, while sodium valproate facilitates, sexual receptivity. Pharmacology, Biochemistry \& Behavior, 46, 1-8.

Frye, C. A., \& MURPHY, R. E. (in press). Antisense oligonucleotides, for progestin receptors in the hypothalamus and glutamic acid decarboxylase in the midbrain, block progesterone-induced lordosis in rats. Behavioural Brain Research.

Frye, C. A., van Keuran, K. R., \& Erskine, M. S. (1996). Behavioral effects of $3 \alpha$-androstanediol: I. Modulation of sexual receptivity and promotion of GABA-stimulated chloride flux. Behavioural Brain Research, 79, 109-118.

Frye, C. A., \& Vongher, J. M. (1999a). GABA , $_{1}$ and $D_{5}$, but not progestin, receptor antagonists and anti-sense oligonucleotides to the ventral tegmental area of cycling rats and hamsters attenuate lordosis. Behavioural Brain Research, 103, 23-34.

Frye, C. A., \& Vongher, J. M. (1999b). Progesterone has rapid and membrane effects in the facilitation of female mouse sexual behavior. Brain Research, 815, 259-269.

GANS, S. E., \& MCCunTock, M. K. (1993). Individual differences among female rats in the timing of the preovulatory LH surge are predicted by lordosis reflex intensity. Hormones \& Behavior, 27, 403-417.

Giordano, A. L., Johnson, A. E., \& Rosenblatt, J. S. (1990). Haloperidol induced disruption of retrieval behavior and reversal with apomorphine in lactating rats. Physiology \& Behavior, 48, $211-214$.

Glaser, J. H., Rubin, B. S., \& Barfield, R. J. (1983). Onset of the receptive and proceptive components of feminine sexual behavior in rats following the intravenous administration of progesterone. Hormones \& Behavior, 17, 18-27.

Grierson, J. P., James, M. D., Pearson, J. R., \& Wilson, C. A. (1988). The effect of selective D1 and D2 dopaminergic agents on sexual receptivity in the female rat. Neuropharmacology, 27, 181-189.

HARDY, D. F., \& DEBOLD, J. F. (1971). Effects of mounts without intro- mission upon the behavior of female rats during the onset of estrogeninduced heat. Physiology \& Behavior, 7, 643-645.

Hull, E. M., Bazzett, T. J., Warner, R. K., Eaton, R. C., \& ThompsON, J. T. (1990). Dopamine receptors in the ventral tegmental area modulate male sexual behavior in rats. Brain Research, 512, 1-6.

Kalra, S. P., Clark, J. T., \& Kalra, P. S. (1988). The role of adrenergic and neuropeptidergic systems in the regulation of male sexual behavior. In A. Negro-Vilar, A. Isidori, J. Paulson, R. Abdelmassila, \& M. P. P. de Castro (Eds.), Andrology and human reproduction (Serono Symposia, Vol. 44, pp. 203-212). New York: Raven.

Kow, L.-M., Mobrs, C. V., \& Pfaff, D. W. (1994). Roles of secondmessenger systems and neuronal activity in the regulation of lordosis by neurotransmitters, neuropeptides, and estrogen: A review. Neuroscience \& Biobehavioral Reviews, 18, 251-268.

Kubli-Garfias, C., \& Whalen, R. E. (1977). Induction of lordosis behavior in female rats by intravenous administration of progestins. Hormones \& Behavior, 9, 380-386.

LISK, R. D. (1960). A comparison of the effectiveness of intravenous, as opposed to subcutaneous, injections of progesterone for the induction of estrous behavior in the rat. Canadian Journal of Biochemical Psychology, 38, 1381-1383.

LUTTGE, W. G., \& WALLIS, C. J. (1973). In vitro accumulation and saturation of ${ }^{3} \mathrm{H}$ progestins in limbic, diencephalic and mesencephalic regions of the mouse brain. Life Sciences, 12, 419-424.

LutTGE, W. G., Wallis, C. W., \& Hall, N. R. (1974). Effects of preand posttreatment with unlabelled steroids on the in vivo uptake of ${ }^{3} \mathrm{H}$ progestins in selected brain regions, uterus and plasma of the female mouse. Brain Research, 71, 105-115.

MAJEWSKA, M. D. (1987). Actions of steroids on neuron: Role in personality, mood, stress, and disease. Integrated Psychiatry, 5, 5258-5273.

Mani, S. K., Allen, J. M. C., Clark, J. H., Blaustein, J. D., \& O'MalLEY, B. W. (1994). Convergent pathways for steroid hormone- and neurotransmitter-induced rat sexual behavior. Science, 265, 1246-1249.

Mani, S. K., Allen, J. M. C., Lydon, J. P. Mulac-Jericevic, B.. Blaustein, J. D., DeMayo, F. J., Conneely, O., \& O’Malley, B. W. (1996). Dopamine requires the unoccupied progesterone receptor to induce sexual behavior in mice. Molecular Endocrinology, 10, 1728-1737.

Mani, S. K., Blaustein, J. D., Allen, J. M. C., Law, S. W., O'MalLEY, B. W., \& CLARK, J. H. (1994). Inhibition of rat sexual behavior by antisense oligonucleotides to the progesterone receptor. Endocrinology, 135, 1409-1414.

McCormick, C. M., Smythe, J. W., Sharma, S., \& Meaney, M. J. (1995). Sex-specific effects of pre-natal stress on hypothalamicpituitary adrenal responses to stress and brain glucocorticoid receptor density in adult rats. Developmental Brain Research, 84, 55-61.

Mermelstein, P. G., \& Becker, J. B. (1995). Increased extracellular dopamine in the nucleus accumbens and striatum of the female rat during paced copulatory behavior. Behavioral Neuroscience, 109. 354-365.

Meyerson, B. J. (1967). Relationship between the anesthetic and gestagenic action and estrous-inducing activity of different progestins. Endocrinology, 81, 369-374.

Meyerson, B. J. (1968). Amphetamine and 5HT inhibition of copulatory behavior in the female rat. Annales Medicine Experimentalis et Biologiae Fenniae, 46, 394-398.

MEYERSON, B. J. (1972). Latency between intravenous injection of progestins and the appearance of estrous behavior in estrogen-treated rats. Hormones \& Behavior, 3, 1-9.

Meyerson, B. J., Carrer, H., \& Eliasson, M. (1974). 5-Hydroxytrytamine and sexual behavior in the female rat. Advanced Biochemical Psychopharmacology, 11, 229-242.

MunN, A. R., SAR, M., \& STUMPF, W. E. (1983). Topographic distribution of progestin target cells in hamster brain and pituitary after injection of $\left[{ }^{3} \mathrm{H}\right] \mathrm{R} 5020$. Brain Research, 274, 1-10.

PAXINos, G., \& WATSON, C. (1986). The rat brain in stereotaxic coordinates. New York: Academic Press.

Rose, J. D. (1990). Tectoreticular neuronal activity associated with behavior and progesterone action during the induction of lordosis responding in hamsters. Society for Neuroscience Abstracts, 16, 924. 
SAR, M., \& STUMPF, W. [E.] (1973). Neurons of the hypothalamus concentrate ${ }^{3} \mathrm{H}$ progesterone or its metabolites. Science, 182, 1266-1268.

Selye, H. (1941). Anaesthetic effects of steroid hormones. Proceedings of Experimental Biological Medicine, 46, 116-121.

SELYE, H. (1942). The antagonism between anesthetic steroid hormones and pentamethylenetetrazol (metrazol). Journal of Laboratory \& Clinical Medicine, 27, 1051-1053.

SietNiEKS, A., \& MEYERSON, B. J. ( 1985). Effect of domperidone on apomorphine inhibition of the copulatory response and exploratory behavior in the female rat. Acta Pharmacologica \& Toxicologica, 57, 160-165.

VONGHER, J., \& FrYE, C. A. (1997, June). Finasteride and epostane reduce lordosis when applied to the midbrain of rats and hamsters. Paper presented at the annual meeting of the Society for Neuroendocrinology, Baltimore.

Ward, I. L., Crowley, W. R., Zemlan, F. P., \& Margules, D. L. (1975). Monoaminergic mediation of female sexual behavior. Journal of Comparative \& Physiological Psychology, 88, 53-61.
Warembourg, M., Poulain, P., \& Jolivet, A. (1992). Progesterone receptor-containing neurons in the guinea-pig mediobasal hypothalamus have axonal projections to the medial preoptic area. Journal of Neuroendocrinology, 4, 273-279.

Whalen, R. E., \& Lauber, A. H. (1986). Progesterone substitutes: cGMP mediation. Neuroscience \& Biobehavioral Reviews, 10, 47 53.

Whalen, R. E., \& LutTge, W. G. (1971a). Differential localization of progesterone uptake in brain: Role of sex, estrogen pretreatment and adrenalectomy. Brain Research, 33, 139-146.

WHALEN, R. E., \& LUTTGE, W. G. (1971b). Role of the adrenal in prefential accumulation of progestins by mesencephalic structures. Steroids, 18, 141-146.

WISE, R. A., \& RoMPRE, P. P. (1989). Brain dopamine and reward. Annual Reviews in Psychology, 40, 191-225.

(Manuscript received April 22, 1998; revision accepted for publication October 6, 1999.) 